\title{
UM PERSONAGEM, DOIS MUNDOS: ISAÍAS CAMINHA EM 1909 E EM 2014
}

\author{
Lizandro Carlos Calegari (UFMS) \\ Anderson Amaral de Oliveira (UFMS)
}

Recebido em 16 mai 2018. Aprovado em 30 ago 2018.
Lizandro Carlos Calegari possui Doutorado e PósDoutorado em Letras pela Universidade Federal de Santa Maria. Tem vários artigos publicados em periódicos especializados no Brasil, na França, nos Estados Unidos, em Portugal e na Dinamarca. Em 2009, foi selecionado pelo Ministério das Relações Exteriores como Leitor Brasileiro em universidade estrangeira (Universidade Eötvös Loránd). Possui diversos capítulos de livros publicados e livros organizados por diferentes editoras no Brasil. Desenvolveu pesquisas sobre a lírica de Carlos Drummond de Andrade e, mais recentemente, tem feito estudos sobre a ficção brasileira pós-64, literaturas marginais e teorias do trauma. De 2009 a 2014, foi professor titular de Literatura da Graduação e do PPGL da Universidade Regional Integrada do Alto Uruguai e das Missões, assumindo os cargos de subcoordenador e de coordenador do Mestrado em Letras. Atualmente, é professor de Língua e Literatura no Colégio Politécnico da UFSM e no Programa de Pós-Graduação em Letras (Mestrado e Doutorado) da mesma instituição.

Anderson Amaral de Oliveira é Professor do curso de Letras português e Inglês da UNIJUÍ e Doutorando em Letras na Universidade Federal de Santa Maria. 
Resumo: Este artigo de cunho literário-comparativo apresenta a investigação aspectos inerentes à construção do narrador Isaías Caminha em duas obras literárias intimamente relacionadas: Recordações do escrivão Isaías Caminha, de Lima Barreto, publicada pela primeira vez em 1909 e A lição de anatomia do temivel Doutor Louison, de Enéias Tavares publicada em 2014. Como metodologia de pesquisa, foi realizada uma análise estrutural das obras, empregando teorias da narratologia como forma de evidenciar aspectos constitutivos de ambas as narrativas, do narrador e personagem. $O$ resultado da análise afirma que a multiplicidade discursiva foi o mecanismo encontrado pelo romancista contemporâneo para possibilitar significações em diferentes níveis diegéticos, diferentemente da obra fonte. Conclui-se que tais relações intertextuais, permitem reabrir diversos diálogos com a história, com o presente e o com futuro da nossa cultura, que encontra em si mesma recursos e motivação para criar novas formas de expressão aproximando séculos de conhecimento acumulado e desafiando novos escritores e leitores.

Palavras-chave: Isaías Caminha; Lição de Anatomia; Dr. Louison; Steampunk; Análise Estrutural; Ficção contemporânea;

Abstract: This comparative literature research article analyses the constitutive elements of narrator Isaías Caminha from two related books: Memories of the recorder Isaías Caminha (Recordações do escrivão Isaías Caminha) by Lima Barreto, first published in 1909; and The anatomy lesson of the dreadful Dr. Louison (A lição de anatomia do temível Doutor Louison by Enéias Tavares published in 2014. As methodology it was carried out a structural analysis by the employment of narratology theories, aiming to evidence constitutive aspects from their narratives, narrator and character. Results point out to discursive multiplicity as the mechanism employed by the 
contemporary author to allow understandings in different diegetic levels, diverse from the source book. It was concluded that intertextual relationships allow to reopen different dialogues with the history, the present and the future of our culture, finding in itself resources and motivation to create new types of expression, bringing closer centuries of accumulated knowledge as well as challenging new writers and readers.

Keywords: Isaías Caminha; The Anatomy Lesson; Dr. Loiuson; Steampunk; Structural analysis; Contemporary Fiction

\section{INTRODUÇÃO}

O processo de construção ficcional considera em sua elaboração as mais diversas metodologias de trabalho, que expressam pela constituição de sua estrutura importantes informações sobre seu processo de criação e visão de mundo o que, consequentemente, permite outros níveis de significação, seja como obra literária autônoma, seja enquanto parte de um coletivo de produções que forma a própria literatura.

Este trabalho de cunho comparativo investiga aspectos inerentes à construção do narrador em duas obras literárias intimamente relacionadas: Recordações do escrivão Isaías Caminha, escrita por Lima Barreto e publicada pela primeira vez em 1909 (doravante referida apenas como Recordações); e A lição de anatomia do temível Doutor Louison, publicada por Enéias Tavares em 2014 (doravante Lição de Anatomia). Ambas as obras possuem como narrador o personagem Isaías Caminha em configurações distintas, estando separadas por 105 anos de diferença. 
Nesse sentido, situa-se como questionamento de pesquisa, de que modo a configuração interna do narrador-personagem relaciona-se com a estrutura de ambas as obras, considerando as diferenças em seu processo de produção. Em Lição de Anatomia, Isaías Caminha ganha um novo enredo, relacionando-se com novos personagens e com outros já consagrados pela literatura brasileira, como Vitória Acauã, Solfieri (de Azevedo) e doutor Benignus, Sérgio Pompeo e Bento Alves, por exemplo.

Para tanto, esse estudo constrói compreensões de como o narrador personagem configura-se nas duas obras escolhidas, considerando o processo de criação ficcional e as escolhas realizadas por autores diferentes, em tempos e espaços distintos, seja de criação, recepção ou do mundo ficcional.

Como metodologia de pesquisa, foi realizada uma análise estrutural das obras, empregando teorias da narratologia como forma de evidenciar aspectos da construção dessas narrativas, do narrador e personagem. Um estudo dessa natureza permite afirmar que obras que fazem parte da herança cultural literária do Brasil como Recordações, permanecem presentes no imaginário cultural nacional, por meio de seus leitores e novos escritores.

\section{O NARRADOR ISAÍAS CAMINHA}

Para a realização do presente trabalho de análise, inicialmente é necessário o estabelecimento de instrumentos e definições teóricas que possibilitem compreender a forma como estas estão estruturadas. Para tanto, é necessário mencionar a tese da "morte do autor" de Roland Barthes (2004), considerando-se a criação e continuação da narrativa sobre o narrador e personagem Isaías 
Caminha. O processo de criação transcende seu autor empírico, o senhor Afonso Henriques de Lima Barreto, ao passo em que é retomado pelo escritor Enéias Tavares, 105 anos depois, libertandose, portanto, das limitações ontológicas de ambos os criadores, transgredindo o pacto ficcional.

A tese de Barthes conceberá o autor enquanto um personagem moderno, considerando para isso a sua função linguística enquanto ente ficcional, enunciador da voz narrativa, atuando na virtualidade da significação, diferindo-se da ação do sujeito empírico que materializa o texto literário enquanto produto cultural. Deste modo, Barthes (2004) considera a escrita como a destruição de toda a voz e de toda a origem, sendo um espaço neutro no qual o sujeito foge e perde-se de toda a identidade, começando precisamente pela identidade do "corpo que escreve".

O processo de escrita, visto por essa perspectiva, dessacraliza o papel do autor, questionando sua ação, bem como seus limites no estabelecimento do pacto ficcional, apontando para a necessidade de uma investigação mais pormenorizada da estrutura da narrativa e do funcionamento de seu narrador. Para Massaud Moisés (2012. p.110),

A partir daí, entra em funcionamento um complexo mecanismo, sujeito à responsabilidade direta do narrador e, indiretamente, do ficcionista. Tal responsabilidade, repartida entre duas entidades virtuais (sabemos que são virtuais depois que a obra se consumou), manifesta-se pela criação de personagens, outros narradores a quem o narrador incumbe a missão de protagonizar o seu destino no espaço que lhes é destinado: o narrador cria outros seres que exercem, por seu turno, o direito de voz.

Adentrando na virtualidade do mundo ficcional, é necessário frisar o papel do narrador enquanto criador e enunciador da voz 
narrativa, pois possibilita o estabelecimento de um novo estatuto de compreensão, guiando e organizando esse mundo, ao mesmo tempo em que responde pela apresentação dos demais entes ficcionais. Do mesmo modo, traz consigo as chaves verbais para o funcionamento desse mundo, que completa sua significação com a ação ativa do leitor no processo de recepção literária. A suspensão momentânea da incredulidade, conceito de Samuel Taylor Coleridge, mencionado por Compagnon (2006, p.98), apresenta-se como a maior condição para que ocorra a entrada e a permanência dentro do universo ficcional.

A importância em desenvolver um estudo que problematize a construção do narrador Isaías Caminha, em Recordações e em Lição de Anatomia, também parte desse deslocamento do autor textual, pois, segundo Aguiar e Silva (2011, p.695), "o narrador não se identifica necessariamente com o autor textual e muito menos com o autor empírico", compreendendo e reconhecendo sua autonomia, no processo de construção intratextual do discurso narrativo, que, por sua vez, dá origem a outros personagens dotados de "vida" própria, independentes ao próprio narrador. A transferência desse "comando fictivo" parte da ação do narrador (MOISÉS, 2012, p.110).

O narrador ocupa espaço privilegiado relacionando o universo diegético com o universo extratextual, pois no caso de Lição de Anatomia é ele quem atualiza a obra primeira por meio da relação de ficcionalização, de ou mesmo a reficcionalização, de loci e personagens que são assim apresentados via discurso narrativo. O mundo povoado por seres e objetos, de eras distintas, é apresentado de maneira lógica e inteligível, sendo reconhecível e quantificável sob a égide de uma "história" (PIMENTEL, 1998, p.10-11). 
A perspectiva do narrador predomina porquanto é a fonte de informação da narrativa, podendo ser o discurso narrativo, a narração pseudofocalizada, que passa pelo filtro da sua perspectiva dos personagens. A partir de Pimentel (1998, p.114), é possível então compreender a diferente dimensão do filtro narrativo de Caminha, de um controle memorial à abertura completa ao discurso de outros narradores em Lição de Anatomia, sem nenhum tipo de mediação de sua parte.

Como forma de compreender o narrador Isaías Caminha, será considerada a classificação proposta por Genette (1995, p.27) a partir de Todorov (1966), cujas categorias elaboradas a partir da gramática do verbo são divididas em Tempo (onde se exprime a relação entre tempo da história); Aspecto (ou a maneira pela qual a história é percebida pelo narrador); e Modo (o tipo de discurso utilizado pelo narrador). Dentro dessa visão teórica e tendo em mente os objetivos desse estudo, será considerado o aspecto Voz, que se encontra dentro da categoria Modo, por justamente possibilitar estudo das relações do sujeito da enunciação com a história (Genette, 1995, p. 29).

Para Aguiar e Silva,

A voz do narrador tem como funções primárias e inderrogáveis uma função de representação. Isto é, a função de produzir intratextualmente o universo diegético - personagens, eventos, etc. - e, uma função de organização e controle das estruturas do texto narrativo, quer a nível tópico (microestruturas), quer a nível transtópico (macroestruturas). Como funções secundárias e não necessariamente atualizadas, a voz do narrador pode desempenhar uma função de interpretação do mundo narrado e pode assumir uma função de ação neste mesmo mundo (2011, p.759) 
A partir dos pressupostos narratológicos que dizem respeito à Voz, será realizada uma análise das obras literárias Recordações e Lição de Anatomia, compreendendo a relação dos narradores com a estrutura das narrativas das quais são oriundos e o significado das relações existentes entre si.

\section{NARRADOR EM RECORDAÇÕES}

A personagem Isaías Caminha surge pela primeira vez na obra Recordações do Escrivão Isaías Caminha, de autoria de Lima Barreto, publicada em 1909. Trata-se de um jovem estudioso e aplicado do interior do estado do Espírito Santo, que vai ao Rio de Janeiro, cidade grande, em busca de suas ambições intelectuais. Relata, por meio de suas memórias, seu processo formativo, desde sua educação familiar, escolar, até sua partida ao Rio de Janeiro em busca do título de doutor. No seio familiar, sofre importantes influências, especialmente da inteligência do pai e da ignorância da mãe:

A tristeza, a compreensão e a desigualdade de nível mental do meu meio familiar, agiram sobre mim de modo curioso: deram-me anseios de inteligência. Meu pai, que era fortemente inteligente e ilustrado, em começo, na minha primeira infância, estimulou-me pela obscuridade de suas exortações (BARRETO, 2010, p.15)

Além da busca intelectual, Caminha reconhece no caminho do conhecimento a verdadeira forma de afirmar-se enquanto sujeito, de modo que, justamente por meio da sua formação intelectual, poderia obter um consistente grau de distinção e reconhecimento social. O empenho de Caminha surge igualmente como uma resposta ao preconceito racial que sofre e o aterroriza por ter a cor da pele escura. Problematiza, a partir disso, o preconceito racial do 
Brasil do início do século $X X$, representado em diversas cenas da obra, nas quais era banalizado e institucionalizado, fazendo parte do discurso de policiais e funcionário públicos.

No fragmento abaixo, retirado de uma reflexão de Caminha, é possível perceber como o título acadêmico representava a tradução de suas qualidades intelectuais em um diploma acadêmico, o reconhecimento social e o acesso a trabalhos mais bem remunerados.

Ah! Seria doutor! Resgataria o pecado original do meu nascimento humilde, amaciaria o suplício premente, cruciante e onímodo de minha cor... Nas dobras do pergaminho da carta, traria presa a consideração de toda a gente. Seguro do respeito à minha majestade de homem, andaria com ela mais firme pela vida em fora. Não titubearia, não hesitaria, livremente poderia falar, dizer bem alto os pensamentos que se estorciam no meu cérebro (BARRETO, 2010, p.21-22)

Além disso, demonstra a consciência de que o preconceito racial pode ser vencido com justiça social, pois, possuindo o devido reconhecimento de sua inteligência e acesso a um padrão de vida melhor, poderia ser ouvido pelas outras pessoas. A forma de contar suas memórias é uma saída igualmente inteligente, de modo que, constitui-se como narrador-personagem de sua própria história ao expressar sua visão de mundo em uma narrativa, empoderando-se por meio da enunciação.

O leitor acessa a obra por essa narrativa, estando a diegese ligada inevitavelmente ao seu discurso. Configura-se, então, como narrador autodiegético, estando envolvido diretamente com o mundo narrado, manifestando através do discurso indireto 
livre, chamado também narrador e personagem. (NÜNING, 2001, GENETTE, 1995, MOISES 2012, AGUIAR E SILVA, 2011). A estrutura vocal, por sua vez está organizada sob focalização desse narrador que emprega como maior recurso a anamnese, de modo que, "recordar é narrar e vice-versa" (NÜNING, 2001, p.144).

Segundo Aguiar e Silva (2011, p.764), a voz dos personagens se manifesta por discurso direto e indireto, diferenciando-se da voz do narrador "(...) quer pela sua "transcrição" comadequados indicadores grafêmicos, quer pela sua introdução com verbos dicendi, quer pela sua caracterização com traços idioletais, socioletais e dialetais que não podem ser atribuídos ao narrador." Nesse sentido, cabe a Caminha direcionar a voz dos outros personagens, considerando a sua focalização, alternando entre o discurso direto dos personagens e sua mediação, além de que sua narrativa está passando pelo filtro da memória no momento da narrativa.

Esse narrador atua enquanto fonte de informações, bem como organizador da narrativa, distribuindo-a em catorze capítulos de narrativas lineares, por meio de uma linguagem clara, coloquial e fluída, sem proporcionar dificuldades interpretativas em sua composição. Em termos ficcionais, a forma da escrita é coerente com a formação e a atuação profissional do narrador, trazendo as influências do gênero jornalístico para estruturação de sua própria narração.

Extratextualmente, a biografia do autor, Lima Barreto, corrobora a influência do gênero jornalístico na elaboração textual, uma vez que esse igualmente trabalhara na redação de jornais no Rio de Janeiro, em um momento em que, segundo Sodré (1999: p.283), literatos confundiam jornalismo com literatura, em um 
sentido negativo, afirmando que a escrita jornalística era obscura e "empolada". Embora Lima Barreto não prezasse pelo preciosismo linguístico, buscava um meio de expressão apropriado aos tempos modernos, ligado às transformações pelas quais a cidade passava, encontrando um equilíbrio entre a linguagem cotidiana e a literária.

As dimensões intra e extratextuais se ligam no prefácio da obra, no qual Lima Barreto borra a ambas intencionalmente, reproduzindo uma carta do personagem Isaías Caminha, apresentando-o como seu amigo e o verdadeiro autor do livro, assumindo apenas o papel de editor. A partir desse momento, já não se fala aqui de Lima Barreto enquanto sujeito empírico e sim como sujeito do discurso e da enunciação, materializado pela literatura. A tese da morte do autor de Barthes mencionada anteriormente tem um exemplo nesse encontro, apenas possível pela ficcionalização.

Perdoem-me os leitores a pobreza da minha narração.

Não sou propriamente um literato, mas não inscrevi nos registros da Livraria Garnier, do Rio, nunca vesti casaca, e os grandes jornais da Capital ainda não me aclamaram como tal - o que de sobra, me parece, são os motivos bastante sérios, para desculparem a minha falta de estilo e capacidade literária.

Caxambi, Espírito Santo, 12 de julho de 1905.

Isaías Caminha

Escrivão da Coletoria.

(BARRETO, 2010, p.13)

O prefácio é intitulado de "Breve notícia" e por meio de seus recursos de metatextualidade, apresenta ao leitor o jogo entre o autor Lima Barreto, o personagem e também narrador Isaías Caminha. 
Nesse mesmo prefácio, Lima Barreto chama a autoridade do crítico José Veríssimo (2010, p.10) para dar credibilidade aos escritos de Caminha, justificando sua qualidade apesar das escolhas estéticas feitas. Desse modo, a linguagem escolhida para a concretização da obra aproxima-se à comunicação cotidiana e, por conseguinte, evadese do academicismo e da retórica dos intelectuais, sendo coerente com o plano de conteúdo, no qual Caminha torna-se jornalista.

Essa história traz, além da organização temática e estrutural da obra conectadas, a representação de um recurso de apresentação temporal presente de forma bastante discreta, de modo que, embora a narração ocorra no passado, a partir da projeção memorial do narrador, em alguns raros momentos, a narrativa retorna para o tempo da escrita com a presença de anacronias narrativas, que segundo Genette (1995, p.34), "consistem em formas de discordância entre a ordem da história e da narrativa constituindo no seu grau zero, quando coincide temporalmente a narrativa e história.". Esses diálogos do passado memorial de Isaías Caminha e de seu presente se dão por meio de elipses (GENETTE, 1995, p. 106). Para Pimentel (1998, p.168), as elipses temporais apresentam um lugar que o leitor deve ocupar, possibilitando a inferência por meio da justaposição de sequências narrativas e de "sua competência para reconhecer aos atores como essencialmente os mesmos apesar das mudanças que sofrem no tempo"

A frase final da obra indica uma abertura de diálogo do próprio memorialista com sua história passada a limpo; o presente da narrativa surge, e por meio desse rasgo temporal em seu grau zero abre-se à possibilidade de refletir o futuro, visto como presente pela modernidade, permanecendo o destino do personagem 
indeterminado. Desse modo, torna o ressurgimento de Caminha em Lição de Anatomia uma transição suave do ponto de vista de uma continuidade literária:

Antes de entrar, olhei ainda o céu muito negro, muito estrelado, esquecido de que a nossa humanidade já não sabe ler nos astros os destinos e os acontecimentos. As cogitações não me passaram... Loberant, sorrindo e olhando-me com complacência, ainda repetiu:

- Tolo!

(BARRETO, 2010, p.205)

A cegueira dos contemporâneos de caminha ao destino visto nos astros, metaforicamente é uma crítica à própria modernidade, cuja fé no advento da ciência positivista apresenta-se como uma forte e inevitável tendência. Assim, o limite do campo temporal da narrativa primeira é marcado pela última cena não proléptica (Genette 1995, p.66-67).

A estética retrofuturista, sob a qual Isaías Caminha retorna em Lição de Anatomia, apresenta, enquanto forma e conteúdo. a extrapolação da modernidade em seus dessobramentos formais e temáticos, permitindo que a obra venha renascer mais de um século depois.

\section{NARRADOR EM LIÇÃO DE ANATOMIA}

O cartão de embarque para o futuro, é dado à Isaías Caminha pelo autor Enéias Tavares (2014), retomando o consagrado personagem criado por Lima Barreto por meio da estética Steampunk. O Steampunk ou punk à vapor, apresenta em Lição de Anatomia o tempo da narrativa de forma retrofuturista, ou nas palavras de Girardot 
e Méreste (2006, p. 3) é o "passado se o futuro tivesse chegado antes." [Tradução minha]. Além da estética baseada em um complexo universo ficcional e tempo histórico característicos, estudos ${ }^{1}$ sobre o tema indicam que a "reciclagem" de personagens de obras clássicas, bem como, de personagens históricos é característica recorrente, que, portanto, apresenta uma apropriação e uma estetização do passado, recontando-o e reficcionalizando-o.

Em Lição de Anatomia, Isaías Caminha possui um papel fundamental à estrutura da narrativa, sendo o suporte para sua ação. Passa-se pouco tempo depois da primeira aventura, dessa vez em 1911, dentro do período de três meses de seu início. Acompanha as investigações de um curioso assassino na cidade de Porto Alegre dos Amantes. Seu interlocutor principal é o doutor Loberant, 'amigo \& patrão', cujas correspondências formam a estrutura epistolar dessa nova narrativa de Caminha.

Caminha é o detentor da narração ao mesmo tempo em que é compilador de todas as informações relacionadas ao caso, controlando o acesso do leitor ao "dossiê Louison", cuja abertura e fechamento das investigações indicam os limites da obra. O dossiê apresenta, para cada capítulo, um narrador diferente, dando ao livro uma forma diferenciada de organização, semelhante a uma moldura, sendo o próprio leitor o sujeito que tem acesso a todo o arquivo. Assim, Lição de Anatomia possui relações textuais em cada capítulo: 
Rita Bailana, Pombiinha, Léoni de Souza, Sérgio Pompeo, Bento Alves, Vitória Acauã, Solfieri de

Azevedo e Dr. Benignus, Ricardo Loberant e
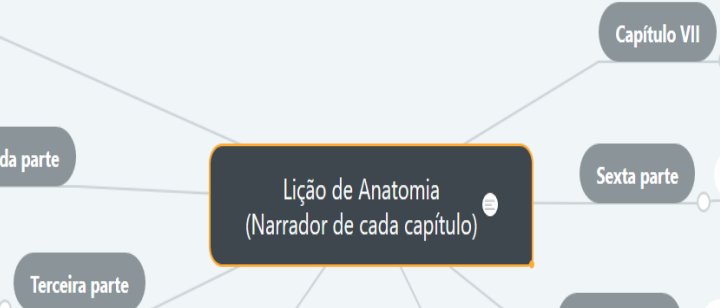

salas Caminha

Issálas Caminha

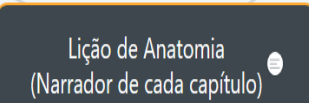

Sexta parte

Dr. Louison

(Narrador de cada capítulo)

Imagem 1: estrutura capitular de Lição de Anatomia. Fonte: o autor (2018).

Em Lição de Anatomia, o narrador Isaías Caminha possui uma função estrutural, organizando a abertura de espaço para outros narradores, conforme a imagem 1. Cada capítulo apresenta o desenvolvimento das ações por meio de gêneros textuais diferentes, embora sejam desdobramentos da forma epistolar clássica, mantendo o apelo a um controle e uma clareza de sua cronologia, típicos de um inventário investigativo. O controle do narrador está em possibilitar o surgimento de funções-articulações e "preenchimentos" na narrativa.

Segundo Barthes (2011, p.33), “[p]ara que uma função seja cardinal, é suficiente que a ação à qual se refere, abra (ou mantenha, ou feche) uma alternativa consequente para o seguimento da história, enfim que ela inaugure ou conclua uma incerteza;", segundo Genette (1995, p.254), o narrador possui diversos papeis, sendo o primeiro deles organizar a história por meio de sua narrativa.

Dessa maneira, Isaías Caminha apresenta sua narrativa como suporte aos outros narradores da obra, cada um adicionando 
uma perspectiva diferente, inclusive, por vezes, contraditórias, proporcionando pontos de conflito na narrativa. Como forma de visualizar melhor os capítulos, seus narradores e seus tipos de discurso, o quadro abaixo expõe uma síntese dessa organização:

\begin{tabular}{|c|c|c|c|}
\hline $\begin{array}{c}\text { Capítulo/ } \\
\text { parte }\end{array}$ & Narrador & Gênero & Tipos de discurso \\
\hline 1 e 6 & Isaías Caminha & Noitário (diário) & Discurso indireto livre \\
\hline 2 & Simão Bacamarte & $\begin{array}{c}\text { Cartas, diários } \\
\text { de trabalho, gravações } \\
\text { robóticas (transcrições), } \\
\text { e diálogos gravados } \\
\text { (transcritos) }\end{array}$ & $\begin{array}{l}\text { Discurso direto livre e } \\
\text { discurso direto }\end{array}$ \\
\hline 3 & $\begin{array}{l}\text { Vitória Acauã, } \\
\text { Rita Baiana, Senhoria, } \\
\text { Léonie de Souza, } \\
\text { Solfieri, Bento Alves, } \\
\text { Pombinha, Loberant, } \\
\text { Sérgio Pompeu, Doutor } \\
\text { Benignus }\end{array}$ & $\begin{array}{l}\text { Cartas, gravações } \\
\text { (transcrições), noitários, } \\
\text { mensagens telegráficas e } \\
\text { telegramas. }\end{array}$ & $\begin{array}{l}\text { Discurso direto livre e } \\
\text { discurso direto }\end{array}$ \\
\hline 4 & $\begin{array}{r}\text { Entrevistador e } \\
\text { Pedro Britto Cândido }\end{array}$ & $\begin{array}{l}\text { Entrevista } \\
\text { (transcrição) }\end{array}$ & Discurso direto \\
\hline $\begin{array}{l}\text { Interlúdio } \\
\text { Dramático }\end{array}$ & $\begin{array}{l}\text { Investigador/relator } \\
\text { e Madame de Quental }\end{array}$ & $\begin{array}{l}\text { Autos de processo/ } \\
\text { Notas }\end{array}$ & $\begin{array}{l}\text { Discurso indireto livre, } \\
\text { discurso indireto }\end{array}$ \\
\hline - & $\begin{array}{l}\text { Beatriz de Almeida } \\
\text { e Entrevistador }\end{array}$ & $\begin{array}{l}\text { Entrevista } \\
\text { (transcrição) }\end{array}$ & Discurso direto \\
\hline 6 & $\begin{array}{c}\text { Pedro Britto } \\
\text { Cândido, Doutor Louison }\end{array}$ & $\begin{array}{l}\text { Entrevista } \\
\text { (transcrição) }\end{array}$ & Discurso direto \\
\hline
\end{tabular}

Segundo Pimentel (1998, p.114), a perspectiva figural orienta o discurso narrativo sob a forma de uma psiconarração consonante, usando como forma de enunciação da voz narrativa, o monólogo narrado, o discurso indireto livre, ou mesmo descrições focalizadas, como formas privilegiadas do relato em uma focalização interna fixa. No que se refere à orientação figural dos personagens ocorre o uso do discurso direto, apresentando-se como monólogos, diálogos, diários e outras formas discursivas. Essas não são mediadas pelo narrador 
e sim pela perspectiva criada a partir da voz dos próprios personagens, mesmo com suas limitações espaço-temporais e cognitivas.

Tal organização proporciona que um elemento comum entre toda a diversidade de gêneros empregados na composição de Lição de Anatomia seja a aplicação de um tom pessoal e confessional, possível pela enunciação sempre em primeira pessoa. Para Genette (1995, p.219), "a carta é, ao mesmo tempo, meio da narrativa e elemento da intriga", sendo assim o foco narrativo contido nelas permite acompanhar a investigação, visto que os crimes já aconteceram. Os noitários [sic] de Caminha abrem a possibilidade do diálogo do passado com o tempo presente da narrativa, sendo o processo de quebra temporal, o possibilitador da alternância do foco narrativo, ora para um personagem ora para outro. Desse modo alterna-se entre o passado da memória e dos registros, e o tempo presente de gêneros como diálogos, entrevistas e suas variantes ora transcritos.

Sobre a organização das obras românticas epistolares, lan Watt (2007, p. 154 e 165) atribui a essas a possibilidade de expressar sentimentos de maneira mais íntima e sincera, de modo que o emprego de cartas informais representara uma ruptura com a perspectiva literária clássica. Ao utilizar essa forma literária epistolar em 2014, Enéias Tavares atualiza a forma da obra original, bem como dá uma nova forma de movimento para o narrador-personagem, pelas diferentes perspectivas de narração, expondo o papel do narrador na contemporaneidade, que vislumbra seu gradual desaparecimento.

Faz-se necessário realizar uma caracterização da identidade desse narrador, considerando o estatuto ficcional particular que 
representa, trazendo consigo as particulares marcas de seu tempo e de seu processo de elaboração, diferindo-se da produção de Lima Barreto, portanto.

Isaías Caminha de Enéias Tavares enquanto narrador é homodiegético, não sendo autodiegético (NÜNING, 2001, GENETTE, 1995, MOISES 2012, AGUIAR E SILVA, 2011). Embora Caminha sustente a obra por sua narração investigativa, tal ação ocorre entorno da ação do doutor Louison. A descrição é vinculada em seus noitários, como variação do tradicional 'diário'. Há, porém, um rompimento com a perspectiva narrativa mononuclear de Caminha de Lima Barreto, permitindo a criação de novas visões acerca da diegese.

Os diversos discursos que brotam a partir da moldura narrativa de Caminha formam o nível hipodiegético, a partir do relato em nível intradiegético (REIS e LOPES, 1988, p. 128). Nesse nível, encontramse as peças da investigação dos crimes do doutor Louison. Caminha compila e estrutura a narrativa, na qual os demais personagens igualmente irão narrar a si próprios. Vale ressaltar que, no decorrer das investigações, há um envolvimento de Caminha não somente em termos de posicionamento, foco e voz narrativos, mas também, dentro da diegese, envolvendo-se com outros personagens, passando a fazer parte do Parthenon Místico.

O clímax da história ocorre com a entrada de doutor Louison no capítulo 6. Desse modo, os capítulos que o antecedem fazem parte de uma estrutura que possibilitará o personagem principal assumir o foco da narrativa em primeira pessoa com o uso de discurso direto, tendo a atenção completa do leitor. A forma e o conteúdo se coadunam de modo a dar o efeito de suspense, desfazendo-se 
no capítulo seguinte com a narração de Isaías Caminha em primeira pessoa, utilizando-se de discurso indireto livre.

Diferentemente de Recordações, Lição de anatomia não se estrutura a partir de uma organização memorial e cronológica de seu narrador, e sim, a partir de uma organização investigativa e jornalística, de maneira que cada um dos diferentes discursos seja colocado em suspense enquanto sua validade e sua credibilidade, exigindo o registro como evidência comprovatória. O exemplo extremo disso é a presença de um interlúdio dramático posterior ao capítulo 4 (apresentação ao clímax), e anterior aos capítulos 5 e 6 nos quais o mistério é revelado. Vale ressaltar que os capítulos 4, 5 e 6 são narrados em discurso direto, nos quais os personagens principais aparecem em ações no tempo presente. O policial Pedro Britto Cândido apresenta uma narrativa para o ocaso, quando Beatriz de Almeida \& Souza e doutor Louison apresentam suas estarrecedoras versões para o caso, de certa forma justificando a narrativa do caso.

Tais contrastes na construção da enunciação narrativa promovem diferentes experiências na percepção da história por parte dos leitores, contribuindo para a culminação do clímax. O Interlúdio dramático dissipa a atenção do leitor em documentos fragmentados, e ideias esparsas para explorar a tensão da entrevista de Beatriz de Almeida \& Souza e o solene testemunho de Louison.

Caminha retoma a narração no último capítulo, endereçando a seu chefe Ricardo Loberant o resultado de suas investigações, compreendendo meta-textualmente seu papel de narrador precário e sua impossibilidade de elaborar uma narrativa que não esteja contaminada com a dos outros personagens: 
As páginas que seguem são a reunião de vários documentos que lançarão luzes sobre o que se passou. São noitários, cartas, relatórios, transcrições e outros construtos textuais de variada autoria que compõem o que nomeei de "Dossiê Louison". Caso eu tivesse a disposição para revisitar essa anatomia narrativa, recortada e disposta em múltiplas partes, ela formaria a base de uma reportagem um tanto mais elaborada e objetiva do que a sua forma atual, prolixa e disforme.

Como não tenho, componho uma escrita ao menos mais neutra e coerente do que os textos publicados nos atuais pasquins brasileiros.

Caberá a você, meu amigo, transformar a imperfeição e a verborragia desses esparsos documentos numa narrativa legível. Desculpe-me se por vezes perder me nesta meta conclusiva, enredado como estou nos meandros da confabulação subjetiva, mas é dever também de um escritor contar não somente o que lhe aconteceu, como igualmente o que sua percepção do acontecido desvela.

Como confio em sua perspicácia de leitor e em sua minúcia de editor, entrego a você o resultado de minha pesquisa para ser alterado e corrigido como achar mais apropriado, para retirar de sua estrutura carnosa o sumo das informações que circundam essa terrível investigação. Trate essas páginas, meu caro Ricardo, como trataria o meu empobrecido espírito, pois é isso que deposito em cada uma de suas linhas, compostas na febre apaixonada das madrugadas (TAVARES, 2014, 288)

Embora partamos do pressuposto de que Isaías Caminha seja um escrivão/escritor, há uma grande mudança em seu papel de narrador, recusando-o ficcionalmente, assumindo a condição de investigador e editor de toda a documentação que compõe a obra. 
Esse ato ficcional representa a possibilidade de que estruturalmente se possa haver a presença de outros narradores.

Portanto, considerando o estatuto próprio de Lição de Anatomia, em relação à Recordações, uma discussão de suas possíveis aproximações e distanciamentos faz-se a seguir.

\section{CONSIDERAÇÕES FINAIS}

A separação temporal entre as duas obras permite obter - distanciamento necessário para visualizar Recordações de Lima Barreto em toda sua potência, dando origem a uma nova representação estética que permitem ponderações sobre o estatuto da criação ficcional, e o diálogo entre o clássico e o contemporâneo. A leitura da palavra e do mundo se entrecruzam, recriando-se e produzindo a cada época novos conjuntos de sentidos, propondo diálogos entre quem somos, quem fomos e quem poderíamos ter sido, sempre em movimento, permitindo que a imaginação humana amplie seus limites.

O papel de Isaías Caminha se redimensiona em Lição de Anatomia, havendo uma radical modificação no papel do narrador, passando da posse do domínio completo da narrativa de origem memorial para uma narrativa multivocal, cuja origem de seu discurso é prioritariamente documental. A mudança na organização discursiva evidencia a fragmentação da consciência do narrador que será representada na forma do romance. Não há mais a noção de totalidade como na arte romântica e realista. A soma das partes não dá conta de representar o todo que permanece em aberto.

Em Lição de Anatomia, sua estrutura epistolar permite o exercício da construção e expressão de discursos múltiplos a partir 
de uma seleção de textos realizada por seu narrador. Dentro de cada texto, os personagens assumem a voz narrativa, tornando-se narradores em primeira pessoa, enquanto em Recordações, a voz dos personagens se possibilita a partir da narração em primeira pessoa de Caminha que conduz o foco narrativo.

Desse modo, a multiplicidade discursiva foi o mecanismo encontrado pelo romancista contemporâneo para possibilitar significações em diferentes níveis diegéticos, diferentemente da obra fonte. Vale ressaltar a importância em se estabelecer relações por meio do comparatismo, aproximando os mecanismos usados na representação estética em uma obra clássica brasileira, permite reabrir diversos diálogos com a história, com o presente e o com futuro da nossa cultura, que encontra em si mesma recursos e motivação para criar novas formas de expressão que justamente promovam esse diálogo, aproximando séculos de conhecimento acumulado.

\section{REFERÊNCIAS}

BARRETO, Lima (2010). Recordações do Escrivão Isaías Caminha. São Paulo: Martin Claret, 2010.

BARTHES, Roland (2004). "A morte do autor". In: O Rumor da Língua. São Paulo: Martins Fontes.

(2011). Introdução à análise estrutural da narrativa. 7.ed. Petrópolis: Vozes.

COMPAGNON, Antoine (2006). O demônio da teoria: Literatura e senso comum. Belo Horizonte: UFMG.

GENETTE, Gerárd (1995). Discurso da narrativa. Lisboa: Vega.

GIRARDOT, Jean-Jacques; MÉRESTE, Fabrice (2006). Le Steampunk: une machine littéraire à recycler le passé, Cycnos. 22(1), mis en ligne le 15 novembre. In http:// revel.unice.fr/cycnos/index.html?id=472. Acesso em 05.Ago. 2018. 
MATANGRANO, Bruno Anselmi (2016). "O olhar contemporâneo na releitura do moderno: A lição de anatomia do temível Dr. Louison". Estudos de Literatura Brasileira Contemporânea, (48), 247-280.

MOISÉS, Massaud (2012). A criação literária: poesia e prosa. São Paulo: Cultrix. NÜNNING, Ansgar (2001). "On the perspective Strucutre of narrative texts: steps toward a Constructivist Narratology". In: PEER, Sillie Van; CHATMAN, Seymor. New perspectives on narrative perspective. New York: State University of New York Press.

PEGORARO, Éverly (2012). "Steampunk: as transgressões temporais negociadas de uma cultura retrofuturista". Cadernos de Comunicação, Santa Maria: 16, 389400. In http://goo.gl/CnqMmf. Acesso em 05.Ago.2018.

PIMENTEL, Luz Aurora (1998). Relato en perspectiva: estudio de teoria narrativa. México: Siglo XXI.

REIS, Carlos; LOPES, Ana Cristina M (1988). Dicionário de Teoria Narrativa. São Paulo: Ática.

SILVA, Vitor Manuel de Aguiar e (2011). Teoria da Literatura. 8.ed. Coimbra: Biblioteca nacional de Portugal.

SODRÉ, Nelson Werneck (1999). História da imprensa no Brasil. Rio de Janeiro: Mauad.

TAVARES, Enéias (2014). A lição de anatomia do temível Doutor Louison. Rio de Janeiro: Casa da Palavra.

WATT, Ian (2007). A Ascensão do Romance: Estudos sobre Defoe, Richardson e Fielding. São Paulo: Companhia das Letras. 